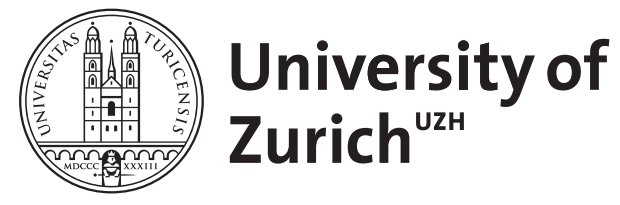

Zurich Open Repository and Archive

University of Zurich

University Library

Strickhofstrasse 39

CH-8057 Zurich

www.zora.uzh.ch

Year: 1994

\title{
L-carnitine improves vascular refilling in haemodialysis patients during
} ultrafiltration

\author{
Záruba, J ; Probst, W ; Binswanger, U
}

DOI: https://doi.org/10.1093/ndt/9.5.587

Posted at the Zurich Open Repository and Archive, University of Zurich ZORA URL: https://doi.org/10.5167/uzh-154097

Journal Article

Published Version

Originally published at:

Záruba, J; Probst, W; Binswanger, U (1994). L-carnitine improves vascular refilling in haemodialysis patients during ultrafiltration. Nephrology, Dialysis, Transplantation, 9(5):587-588.

DOI: https://doi.org/10.1093/ndt/9.5.587 
involvement and with the following laboratory findings of blood and urine examinations: BUN, creatinine, complement component $C 3$, and immunoglobulins. Seven cases (46.6\%) had renal involvement with microscopic haematuria $(n=4)$, acute nephritic syndrome $(n=2)$, macroscopic haematuria and nephrotic syndrome $(n=1)$.

MHC antigens were determined by tissue typing laboratory using standard microlymphocytotoxicity assay [3]. The relative risks for each HLA antigen for HSP were calculated by means of ratios of study and control groups (relative risk $=($ antigen + patient $\% \times$ antigen - control $\%) /($ antigen - patient $\% \times$ antigen + control $\%)$ ). Confidence interval of $99 \%$ was $0.767-3.000$ for these relative risk values.

In HSP patients, HLA-A3, HLA-A9, HLA-Bw35 with relative risks higher than $99 \%$ maximum confidence limit (3.000) showed the strongest association with HSP (Table 1). We have been unable to find an association between MHC antigens and the studies in first-degree relatives, because relative risks of all antigens in each locus were below 3.000. No common haplotype was found in both patient and family studies.

HSP has been linked to HLA Bw35 and HLA-DR4 by some authors, although several investigators have been unable to find an association [1]. There has been still much speculation on the relation between HSP and MHC antigens. Our results agree in part with previous findings by others, but also include differences from recent studies such as the significance of HLA-A3 and HLA-A9.

All these observations demonstrate that disease susceptibility genes may play a role in the pathogenesis of HSP. We have described some genetic markers for HSP in Turkish population and tried to compare them with previous findings.

Ege University, The Medical School, Dept of Pediatric Nephrology

Bornova-Izmir, Turkey
S. Mir

N. Kutukculer M. Coker

A. Keskinoglu

1. Bergstein JM. Henoch-Schðnlein purpura. In: Behrman RE, Vaughan CV, ed. Nelson Textbook of Pediatrics. 13th edn. WB Saunders, Philadelphia, 1987; 1123-1124

2. Muller CA, Markovic-Lipkovski J, Risler T, Bohle A, Muller GA. Expression of HLA-DQ,-DR and DP antigens in normal kidney and glomerulonephritis. Kidney Int 1989; 35: 116-124

3. Colombe BW. Histocompatibility testing. In: Stites DP, Terr AI, ed. Basic and Clinical Immunology. 7th edn. Prentice Hall International, London, 1991, pp. 295-311

Table 1. The relative risks of HLA antigens in Turkish children with Henoch-Schơnlein purpura

$\begin{array}{cllll}\text { HLA-A1 :0.9 } & \text { B5 }: 1.8 & \text { Cw2:1.3 } & \text { DR1 :0.3 } \\ \text { A2 :0.4 } & \text { B8 :1.2 } & \text { Cw3:0.4 } & \text { DR2 :0.3 } \\ \text { A3 :3.6* } & \text { B12 :1.3 } & \text { Cw4:1.5 } & \text { DR3 :0.6 } \\ \text { A9:3.1* } & \text { B14 :1.3 } & \text { Cw6:0.2 } & \text { DR4 :0.9 } \\ \text { A30:1.2 } & \text { B17 :1.8 } & & \text { DR5 :0.4 } \\ \text { A10:0.4 } & \text { B21 :1.2 } & & \text { DR7 :0.3 } \\ & \text { Bw35:3.8* } & & \text { DR11 :0.2 } \\ & \text { Bw73:2.5 } & & \text { DRw53:0.2 } \\ & \text { Bw4:0.2 } & & \\ & \text { Bw6 :0.6 } & & \\ & \text { B7 :0.6 } & & \\ & \text { B13 :0.6 } & & \\ \text { B40 :0.6 } & & \\ & \text { B27 :0.2 } & & \\ & \text { B37 :0.2 } & & \\ \end{array}$

*99\% confidence interval: 0.767-3.000.
L-carnitine improves vascular refilling in haemodialysis patients during ultrafiltration

Sir,

Patients on maintenance haemodialysis are reported to exhibit disturbed carnitine metabolism and carnitine deficiency [1]. There are reports that carnitine supplementation in patients undergoing chronic haemodialysis may lead to the amelioration of uraemic anaemia and improved exercise tolerance. Recently carnitine was also found to reduce the rate of intradialytic hypotensive episodes and muscle cramps [2].

Carnitine is a peptide synthesized in liver, kidney, and brain from the essential amino acids lysine and methionine. It facilitates the entry of long-chain fatty acids into mitochondria and therefore serves as an important metabolic cofactor. Skeletal and cardiac muscle and the kidneys rely primarily on fatty acids as an energy substrate. Recently it has been hypothesized that carnitine also has a vascular mechanism of action [3]. According to this hypothesis 'external' carnitine plays a role in metabolic fine regulation at a cellular level by promoting local blood flow under conditions of metabolic stress through changes in vascular endothelial and smooth muscle cells.

During haemodialysis excess accumulated body water is removed from haemodialysis patients by using ultrafiltration. During this process fluid is first removed from the vascular compartment. There are various compensatory haemodynamic mechanisms to counteract this depletion of blood volume in order to preserve blood pressure and tissue perfusion. They include decreased venous capacitance, increased cardiac rate and contractility, and increased vascular resistance. In addition a shift of fluid is initiated from the extravascular to the vascular compartment. An imbalance between the rate of this vascular refilling and the ultrafiltration rate can result in clinically overt hypovolaemia [4].

It has been suggested that L-carnitine might improve tolerance to ultrafiltration. In order to study the mechanism behind this, we measured vascular refilling during haemodialysis. Ten patients undergoing maintenance haemodialysis were studied prior to carnitine supplementation and after 4 weeks of carnitine therapy. One gram of L-carnitine was administered i.v. after each dialysis session. All patients were dialysed thrice weekly with high-flux dialysers, the dialysis time being 7.5 or $9 \mathrm{~h}$ per week, according to the patients $\mathrm{Kt} / \mathrm{V}$ values. Eight patients were on acetate and two on bicarbonate dialysis. All patients were normotensive at the time of the study, and nine were on antihypertensive medication (calcium-channel blockers and/or ACE inhibitors, one patient was on beta blockers). Patients with diabetic nephropathy were excluded.

The rate constant of vascular refilling was calculated from the change in blood volume and colloid-osmotic pressure and was normalized for $50-\mathrm{kg}$ lean body mass $(\mathrm{Lp}=$ $\left.\mathrm{ml} \times \mathrm{min}^{-1} \times \mathrm{mmHg}^{-1} \times 50 \mathrm{~kg}^{-1}\right)$ [5]. The relative change in blood volume was monitored continuously by means of ultrasound velocity and the change in colloid-osmotic pressure was calculated from plasma protein concentrations. At the beginning of the dialysis session the patients were subjected to an 'ultrafiltration pulse' for $20 \mathrm{~min}$. The volume ultrafiltered during this 'pulse' was equivalent to the necessary ultrafiltration-volume per hour to reach the patients ideal predialysis weight. After 4 weeks of carnitine supplementation the serum free carnitine increased in all patients from $43.6 \pm 11.3$ to $149.8 \pm 58.9 \mu \mathrm{mol} / \mathrm{l}(\mathrm{M} \pm \mathrm{SD}$, paired $t$ test, $P<0.02)$. Lp increased significantly in six of 
10 patients from $4.54 \pm 0.95$ to $9.09 \pm 2.45 \quad(\mathrm{M} \pm \mathrm{SD}$, $P<0.002$, paired $t$ test). This corresponded to a mean increase of more than $100 \%$. In the remaining four patients we observed a decrease in $L p$ of $5.62 \pm 0.56$ to $3.36 \pm 1.34$ $(\mathrm{M} \pm \mathrm{SD})$. There were no differences in pre- and postsupplementation carnitine, other laboratory findings, blood pressure, interdialytic weight gain, medication, and dialysis modality between the two groups.

This study has shown that a majority $(60 \%)$ of patients have increased vascular refilling after carnitine therapy. In selected patients L-carnitine might contribute to better ultrafiltration tolerance during haemodialysis. This might be due to an improved regional blood flow distribution, through its extracellular functions apart from its role in fatty acid metabolism [6]. These may lead to the promotion of local blood flow and an increased vascular refilling rate. We were unable to identify any different characteristics in the non-responders. Further research is needed to determine the subgroup of patients who benefit from carnitine supplementation and whether this leads to long-term haemodynamic stability on dialysis.
Division of Nephrology,

Department of Internal Medicine,

J. Záruba

University Hospital Zurich,

Switzerland

W. Probst

U. Binswanger

1. Wanner Ch, Horl WH. Carnitine abnormalities in patients with renal insufficiency. Pathophysiological and therapeutical aspects. Nephron 1988; 50: 89-102

2. Ahmad S, Robertson Th, Golper ThA et al. Multicenter trial of L-carnitine in maintenance hemodialysis patients. II. Clinical and biochemical effects. Kidney Int 1990; 38: 912-918

3. Dubelaar ML, Lucas CMHB, Holsmann WC. The effect of L-carnitine on force development of the latussimus dorsi muscle in dogs. $J$ Cardiol Surg 1991; 6: 270-275

4. Keshaviah PR, Ilstrup KM, Shapiro FL. Dynamics of vascular refilling. Progr Artif Organs 1983; 506-510

5. Schneditz D, Roob J, Oswald M et al. Nature and rate of vascular refilling during hemodialysis and ultrafiltration. Kidney Int 1992; 42: $1425-1433$

6. Hülsmann WC, Dubelaar ML. Carnitine in metabolism of paced cardiac and skeletal muscles: prevention of acidosis and improvement of vascular flow. In: Ferrari R, ed. L-carnitine and its Role in Medicine: From function to therapy. 1992: 345-358 